
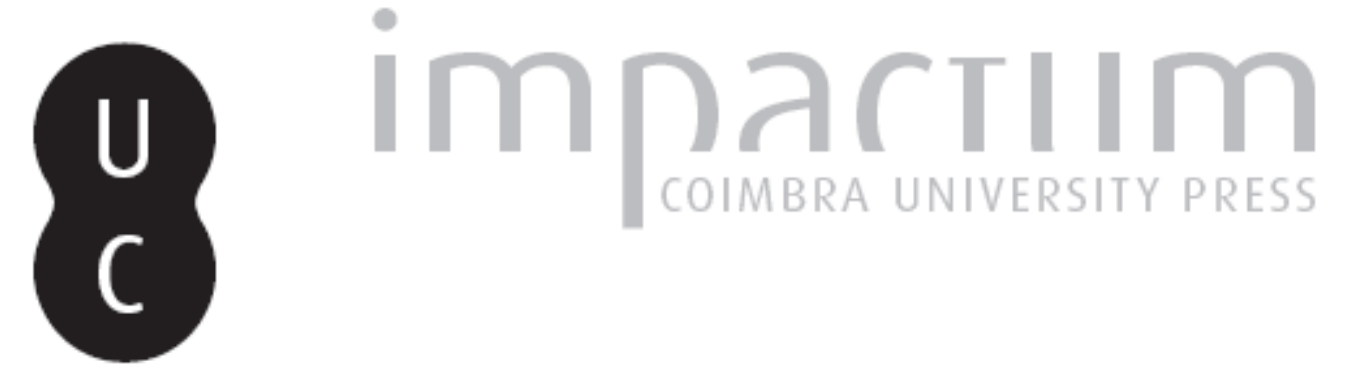

\title{
Região centro de Portugal: duas décadas de incêndios florestais
}

\section{Autor(es): Nunes, Adélia}

Publicado por: Associação Portuguesa de Riscos, Prevenção e Segurança

URL persistente:

URI:http://hdl.handle.net/10316.2/40091

DOI:

DOl:https://doi.org/10.14195/1647-7723_9_9

Accessed : $\quad$ 26-Apr-2023 07:40:50

A navegação consulta e descarregamento dos títulos inseridos nas Bibliotecas Digitais UC Digitalis, UC Pombalina e UC Impactum, pressupõem a aceitação plena e sem reservas dos Termos e Condições de Uso destas Bibliotecas Digitais, disponíveis em https://digitalis.uc.pt/pt-pt/termos.

Conforme exposto nos referidos Termos e Condições de Uso, o descarregamento de títulos de acesso restrito requer uma licença válida de autorização devendo o utilizador aceder ao(s) documento(s) a partir de um endereço de IP da instituição detentora da supramencionada licença.

Ao utilizador é apenas permitido o descarregamento para uso pessoal, pelo que o emprego do(s) título(s) descarregado(s) para outro fim, designadamente comercial, carece de autorização do respetivo autor ou editor da obra.

Na medida em que todas as obras da UC Digitalis se encontram protegidas pelo Código do Direito de Autor e Direitos Conexos e demais legislação aplicável, toda a cópia, parcial ou total, deste documento, nos casos em que é legalmente admitida, deverá conter ou fazer-se acompanhar por este aviso.

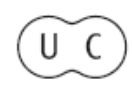




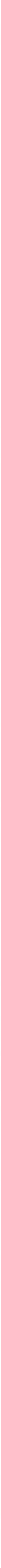




\title{
Região centro de Portugal: duas décadas de incêndios florestais
}

\author{
Adélia Nunes*
}

\begin{abstract}
Resumo:
A Região Centro (R.C) de Portugal tem sido, nestes últimos 20 anos, a mais devastada pelos incêndios florestais, apesar de registar fortes variações internas na sua ocorrência e gravidade. Nestas circunstâncias, analisar a evolução temporal e o comportamento espacial dos fogos, ocorridos entre 1980 e 2000 , e desvendar alguns dos aspectos geohumanos da sua incidência, são os principais objectivos deste trabalho.

Para concretizar este último objectivo socorremo-nos de uma metodologia que associa, através do Coeficiente de Correlação Linear de Bravais-Pearson, informações ambientais e sócio-económicas com os incêndios florestais, com a intenção de medir a intensidade da respectiva relação.

Palavras-chave:
\end{abstract}

Incêndios florestais, Região Centro, factores geohumanos, Coeficiente de Correlação Linear.

\section{Résumé:}

La Région Centre du Portugal a eu, durant les derniers 20 ans, dévastée par les incendies de forêt, malgré le registre d'importantes variations internes en occurrence et gravité. Dans ces circonstances, analyser l'évolution temporelle et le comportement spatial des feux, enregistrés entre 1980 et 2000 , et discerner quelques aspects géographiques et humains de son incidence, sont les principaux objets de ce travail.

Pour concrétiser le dernier, l'autour use une méthodologie qui associe, à travers du Coefficient de Corrélation Linaire de Bravais-Pearson, informations environnementales, sociales et économiques avec les incendies de forêt, avec le propos d'évaluer l'intensité de la respective relation.

Mots-clés:

Incendies de forêt; Região Centro; Facteurs géographiques et humains, Coefficient de Corrélation Linaire

\section{Abstract:}

The Central Region has been, in the last 20 years, the main destructed Portuguese area by forest fires, although the internal significant variation in its manifestation and gravity. In those situations, analysing the temporal evolution and spatial comportment of fires, happened between 1980 and 2000, discerning some of the geographical and human aspects, are the first objectives of this work.

To concretising the last aim we used a methodological that combine, with a linear correlation coefficient of Bravais-Pearson, environmental, social and economical information with a forest fires, with the intention to evaluate her relation intensity.

Key words:

Forest fires; Região Centro, Geographical and human factors,

Linear correlation coefficient

\section{Introdução}

Os fogos florestais continuam, neste virar de milénio, a ser assunto de investigação de diversas áreas científicas e de múltiplas instituições, as quais sugerem, de forma peremptória e unânime, que a estratégia mais adequada para reduzir os efeitos indesejados da sua manifestação se encontra no aperfeiçoamento das ferramentas de prevenção. O melhoramento e a concretização destas técnicas exige, por seu turno, o conhecimento do quadro espaço-temporal dos incêndios e a compreensão dos múltiplos factores que estão na génese da sua ocorrência e desenvolvimento, de modo a que as medidas a implementar sejam congruentes e praticáveis.

* Instituto de Estudos Geográficos. Faculdade de Letras. Universidade de Coimbra.
E quando se examina a distribuição geográfica das áreas ardidas em Portugal continental constata-se que a Região Centro (R.C) tem sido a mais flagelada pelas chamas (L. Lourenço \& P. MALTA, 1993, p. 265), motivo pela qual centramos esta análise nessa área. Assim, o trabalho que se apresenta surge com o triplo objectivo de averiguar a evolução temporal e o comportamento espacial do incêndios florestais que ocorreram na R.C do país, nestas duas últimas décadas (1980-20̉00), mas igualmente com a finalidade de desvendar alguns dos aspectos físico-humanos da sua incidência e gravidade.

Mas, porque neste território de vincados contrastes morfológicos, de características climáticas heterogéneas e com uma presença desigual de população, se denotam fortes variações na ocorrência e gravidade dos incêndios, resulta interessante a sua observação, numa primeira 
abordagem, em unidades territoriais mais ou menos homogéneas (Nut's III) e depois a sua apreciação por concelho. Do mesmo modo, serão cotejados os valores absolutos e os valores relativos, obtidos da sua ponderação com a área efectivamente ocupada por cada uma destas unidades.

No intuito de complementar esta análise tratou-se, além dos valores médios anuais, a respectiva variabilidade interanual (1980-2000) calculando para o efeito al guns parâmetros estatísticos, nomeadamente a média, a mediana e odesvio-padrão, os quais permitem avaliar a regularidade da distribuição ao longo destes anos, em cada um dos municípios da R.C.

Esta apreciação espacial e temporal dos incêndios, quer do ponto de vista da sua ocorrência quer no que concerne à sua dimensão, a partir de uma série de 20 anos, permite ainda concretizar vários objectivos, entre os quais se destaca: zonificação das áreas mais afectadas; observação de tendências; relacionamento do número de incêndios e sua dimensão com diversas variáveis físico-naturais e sócio-económicas. Através do cruzamento de todas estas informações será possível identificar as unidades mais vulneráveis ao fogo, discernir alguns dos principais factores responsáveis pelas suas origens e intervenientes no seu desenvolvimento, mas também avaliar em que medida os recursos e os equipamentos de prevenção e de extinção se têm ajustado à realidade observada.

É óbvio que a complexidade dos fenómenos aqui tratados, pela interpenetração de factores humanos e naturais, faz com que seja essencial um bom conhecimento das características específicas de cada concelho, sendo este trabalho apenas um pequeno contributo para a sua análise.

\section{Quadro evolutivo e incidência espacial}

\subsection{Análise por Nut III}

A observação do gráfico da figura 1 evidencia de modo claro a tendência geral ascendente do número de incêndios deflagrados emcada ano, designadamente até 1995. Nos dois anos que se seguem (1996-97) assiste-se a uma quebra relevante no somatório anual de ocorrências, desencadeando-se a partir de então um novo ciclo crescente. Em termos absolutos, as unidades territoriais que ao longo destas duas décadas mais têm cooperado no agravamento anual dos fogos na R.C, mais de 2700 em média, têm sido a região do Dão-Lafões e a Beira Interior Norte, ao acumularem respectivamente $24,4 \%$ e $18,5 \%$ de ocorrências, isto é um valor médio anual de 665 e 502 incêndios.

Em relação às áreas ardidas (figura 2), são de destacar certos anos pelo total de hectares consumidos pelo fogo. Em primeiro lugar sobressai o de 1991, com aproximadamente 120000 ha incinerados, cerca de metade distribuídos pelos municípios do Pinhal, Interior Sul e Interior Norte. Os anos de 1985, 1990 e 1995, com 105000 ha, 87000 ha e 85000 ha lavrados pelo fogo, respectivamente, surgem na sequência e revelaram-se especialmente calamitosos para a Beira Interior Norte, ao arrebatarem anualmente mais de 20000 ha do total afectado pelo fogo.

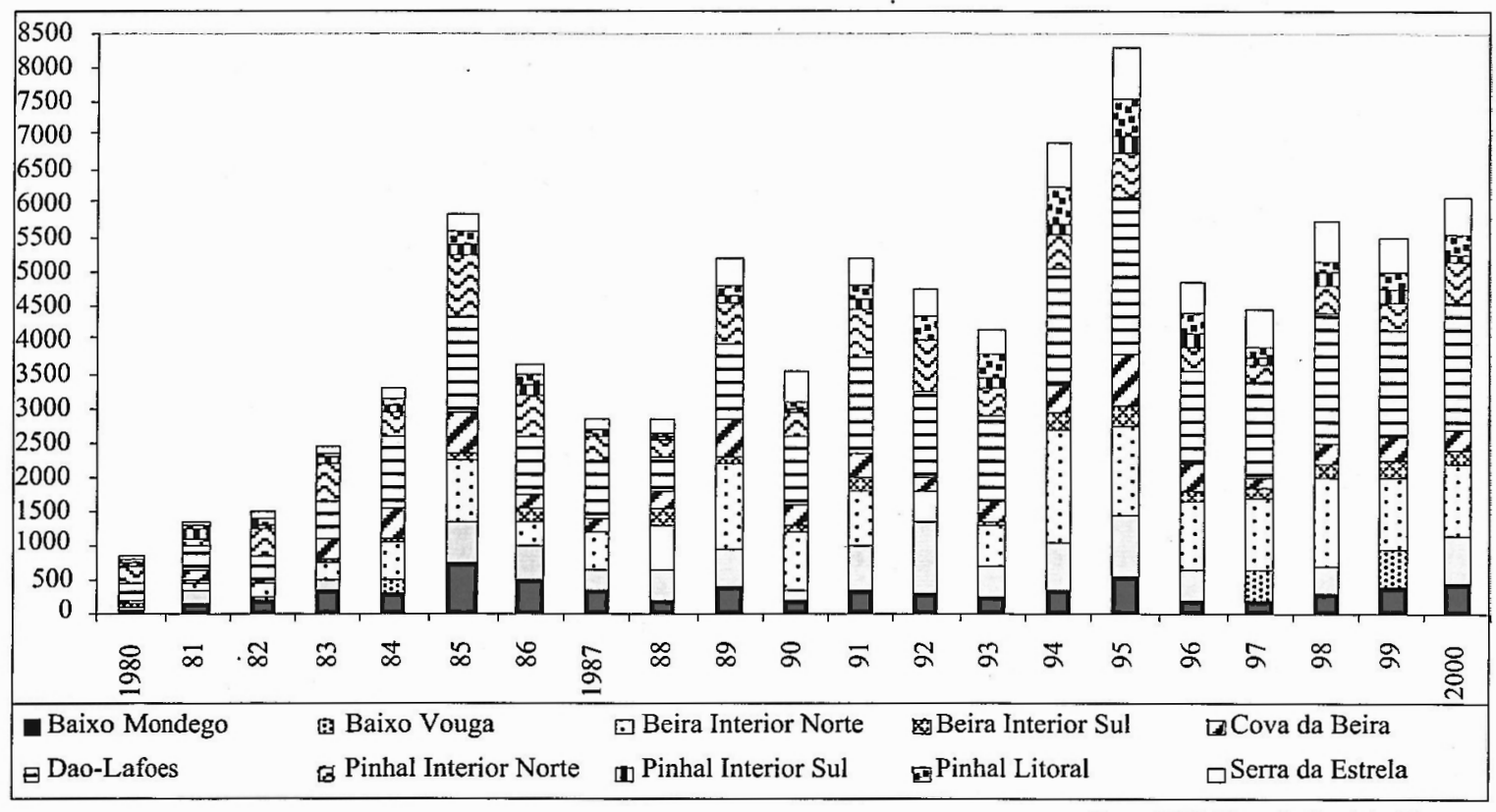

(Fonte: DGF, Direcção Geral das Florestảs)

Fig. 1 - Evolução do número de ocorrências na Região Centro. 
Dos cerca de 49000 hectares que ardem em média por ano (1980-2000) nesta região, cerca de metade repartiram-se por duas unidades: a Beira Interior Norte (28\%) e o Pinhal Interior Norte $(20 \%)$, ao passo que ñas restantes a quota-parte de participação oscilou entre os $2.5 \%$ do Pinhal Litoral e os $15 \%$ da Sub-região do Dão-Lafões. Desse volume médio anual afectado pelo fogo, cerca de $55 \%$ corresponde a associações vegetais cuja espécie predominante é o pinheiro bravo, enquanto os restantes $45 \%$ foram qualificados como matos.

A maior porção de povoamentos ardidos, cerca de $28 \%$, ocorreu na sub-região do Pinhal Interior Norte enquanto a Beira Interior Norte participou com mais de $46 \%$ do total de matos carbonizados.

A espacialização dos valores relativos destas duas variáveis, ou seja donúmero médio de ocorrências por cada $100 \mathrm{~km}^{2}$ e da percentagem média incinerada anualmente, em relação à área da unidade administrativa, introduz uma série de alterações sendo de destacar o emergir da Serra da Estrela, com aproximadamente 27 incêndios $/ a n o / 100 \mathrm{~km}^{2}$. Na sequência, com 19 e 17 fogos/ano/ $100 \mathrm{~km}^{2}$ surgem, respectivamente as sub-regiões do Dão-Lafóes e do Baixo Vouga.

As diferenciações geográficas no que se refere à percentagem média ardida põe em destaque a mesma unidade, ou seja a Serra da Estrela, ao ver lavrado pelo fogo, em cada ano, $4.4 \%$ do respectivo território. Na sequência, surgem o Pinhal Interior Norte $(3.7 \%)$ e a Beira Interior Norte (3.4\%). Em contrapartida, os concelhos da Beira Interior Sul, do Baixo Vouga e do Pinhal Litoral são, em termos relativos, os menos afectados pelo fogo pois o respectivo território percorrido pelas chamas é, em média, inferior a $1 \%$.

A decomposição das áreas anualmente percorridas pelo fogo em função das associações vegetais dominantes, ou seja em matos e povoamentos, revela outros dados curiosos, ao contrapor a Serra da Estrela e a Beira Interior Norte, onde ardem principalmente matos, com as sub-regiões de Pinhal, Interior Norte e Interior Sul, cuja biomassa consumida se constitui maioritariamente de formações monoespecíficas de pinheiro bravo, ainda dominantes na composição vegetal destes concelhos.

\subsection{Análise por concelho}

No seguimento da observação dos dados por concelho, apesar se adoptar a utilização dos valores relativos obtidos através da ponderação do número de incêndios e do conjunto ardido pela área administrativa municipal, os quais permitem uma certa homogeneização das variáveis, apresentamos uma breve reflexão baseada nos respectivos valores absolutos.

A apreciação global dos incêndios no decurso destas duas décadas põe em evidência desfasamentos

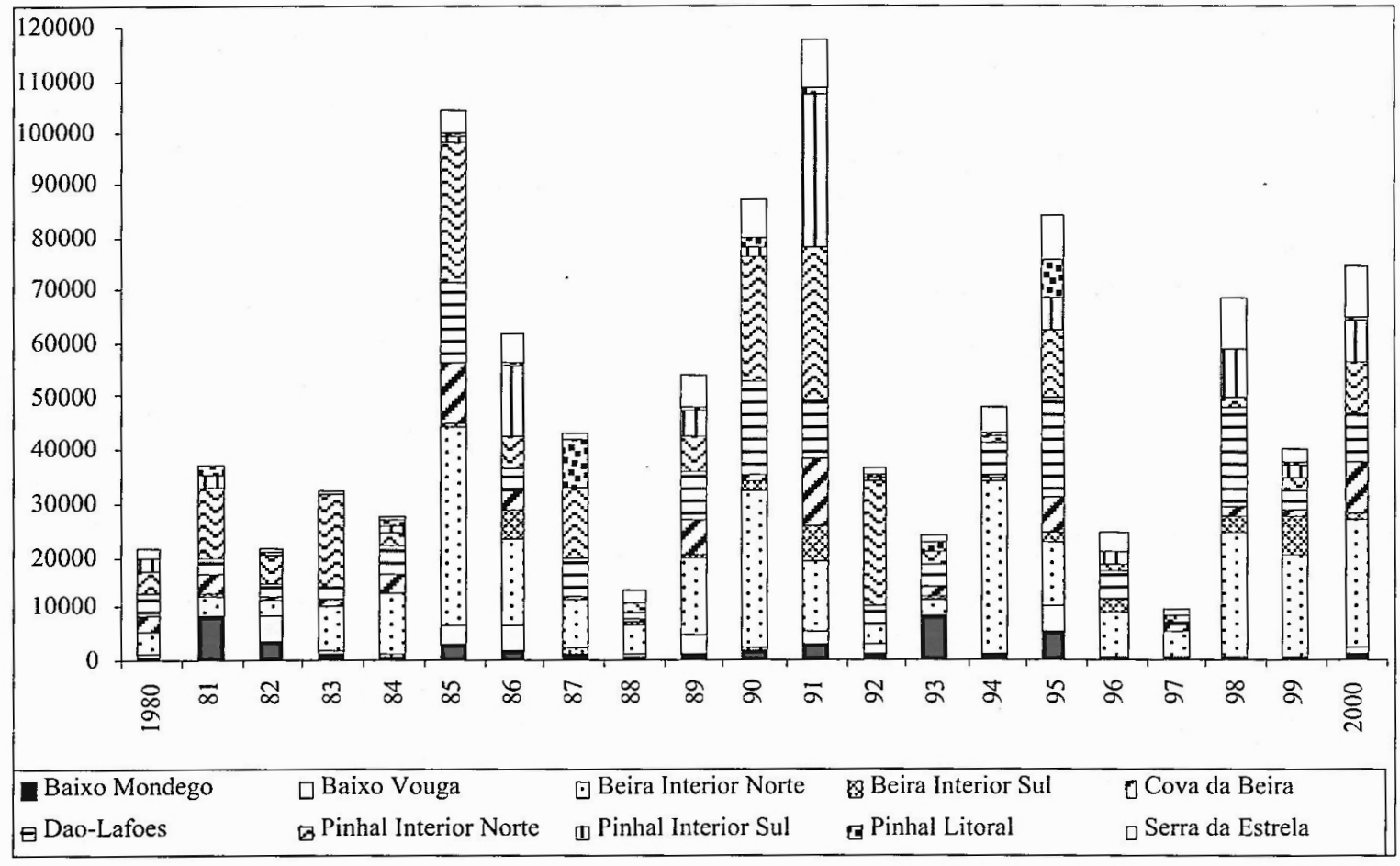

Fig. 2 - Evolução da área ardida (ha) na Região Centro 
espaciais relevantes, destacando em termos absolutos o município de Viseu ao registar um valor médio anual de 286 ocorrências, seguido de longe pelo de Gouveia com 150, do da Guarda com 147 e do Sabugal com 142 fogos (figura 3 ).

Na dispersão territorial das estatísticas referentes aos valores relativos por concelho toma primazia, com 91 incêndios anuais por cada $100 \mathrm{~km}^{2}$, Oliveira do Hospital, seguindo-se Ovar (72.6), Viseu (61.5) Gouveia (53.8) e Carregal do Sal (51.5). No extremo oposto, ou seja com menos de 10 incêndios/ano/ $/ 100 \mathrm{~km}^{2}$ sobressai um conjunto de concelhos, cuja localização geográfica ocorre dominantemente no Litoral, mas também em algumas áreas do Interior, abarcando em especial os concelhos que se integram na Superfície de Castelo Branco (ver figura 5 com a localização dos concelhos da Região Centro).

Com a determinação conjunta da diferença entre a média e a mediana e do desvio-padrão, para cada um dos concelhos, sintetizam-se descritivamente as variações interanuais no número de ocorrências. As discrepâncias entre a média-mediana, além de nos fornecerem indicações sobre o grau de significância da média, permitem-nos inferir sobre a forma, simétrica ou assimétrica, das distribuições anuais.

Assim, e no que se refere à incidência relativa de incêndios, apesar de prevalecerem os desvios positivos, os quais denotam uma assimetria positiva e o predomínio de efectivos abaixo da média, são de destacar, para 15 concelhos, diferenças negativas, realçando a preponderância de efectivos de valor superior à média. As diferenças positivas, de particular relevância nos concelhos de Carregal do Sal, Mangualde, Nelas e também em Ílhavo, denunciam o fraco significado do valor médio, usualmente empregue nos trabalhos de investigação, edenotam a superioridade de efectivos abaixo da média.

Em contrapartida, os valores médios determinados para os concelhos que se situam particularmente nas sub-regiões que contactam com o oceano Atlântico e ainda na Beira Interior Sul, resultam significativos, pois as disparidades entre estes dois parâmetros são pouco expressivas.

A variabilidade interanual, destacada pelo desvio- padrão, mostra-se especialmente elevada em Oliveira do Hospital, ao registar nestas duas décadas um valor de 51 incêndios/ano $/ 100 \mathrm{~km}^{2}$; em Ovar, Gouveia, Carregal do Sal, Nelas e $\mathrm{S}^{\text {ta }}$ Comba Dão os valores são igualmente contrastantes. Os valores mínimos de desvio-padrão, que acusam as menores oscilações na densidade anual de incêndios coincidem naturalmente com os municípios que registam menos fogos florestais (figura 3 ).

Relativamente à área ardida (figura 4), sobressaem desde logo dois concelhos: o da Guarda com um valor médio anual de 4113 ha ardidos e o do Sabugal com um total de 3753 ha. Por ordem de importância, outros se lhe associam: Pampilhosa da Serra (2223 ha), Covilhã (2145 ha) e Arganil (2018).

A distribuição espacial da percentagem média ardida anualmente em relação à respectiva superfície administrativa põe em evidência um conjunto de concelhos como sendo os mais martirizados pelas chamas: Arganil e Guarda tomam a dianteira com $6.1 \%$, a que se segue Gouveia com $5,8 \%$, Oliveira do Hospital com 5,3\%, .Miranda do Corvo e Oleiros com 5.1\%, o Sabugal e a Pampilhosa da Serra com $5 \%$. A repartição intra-concelhia desta variável revelanos ainda outras unidades particularmente vulneráveis ao fogo pois a respectiva área média anual incinerada, em relação à superfície total, supera os $4 \%$ : Pedrogão Grande, Fornos de Algodres, Figueiró dos Vinhos, Góis, Seia, Vila Nova de Paiva e Vila Nova de Poiares.

$\mathrm{Na}$ confrontação dos valores médios com os medianos os resultados apurados são todos positivos e oscilam entre 0 e $4.7 \%$, indicando o predomínio, nestes 20 anos analisados, de efectivos inferiores ao revelados pela média final. As maiores diferenças assinalam-se em Arganil, Figueiró dos Vinhos, Góis, Miranda do Corvo, Oleiros, Sever do Vouga, Vila de Rei, Pedrogão Grande e Vila Nova de Poiares, cuja média final terá sido determinada por um ou dois anos intensamente fustigados pelos incêndios.

A avaliação do desvio-padrão permite corroborar a forte variabilidade interanual nas percentagens relativas de área ardida pois os valores máximos coincidem, de um modo geral, com os concelhos em que a média se revela pouco representativa. Não obstante, os elevados valores de desvio-padrão apurados para outros municípios denunciam, identicamente, a grandeheterogeneidade na expansão dos fogos florestais e consequentemente na percentagem de área ardida. $\mathrm{Na}$ Batalha, em Castanheira de Pêra, em Manteigas e na Pampilhosa da Serra os desvios-padrão são superiores a $8 \%$ e encontram-se nitidamente influenciados pela ocorrência anómala de incêndios em um ou mais anos.

No extremo oposto, ou seja com uma variabilidade interanual inferior a $1 \%$ de área ardida individualizase um grupo de concelhos, que coincide genericamente com os menos flagelados pelas chamas, logo com valores anuais que poderão ser classificados como insignificantes.

A apreciação conjunta da figura 4, representativa do comportamento espaço-temporal das manchas incineradas desde 1980, parece denunciar uma certa periodicidade anual nas percentagens de território ardido e também uma certa tendência cíclica dos incêndios em alguns dos concelhos da R.C. 
territorium 9.2002

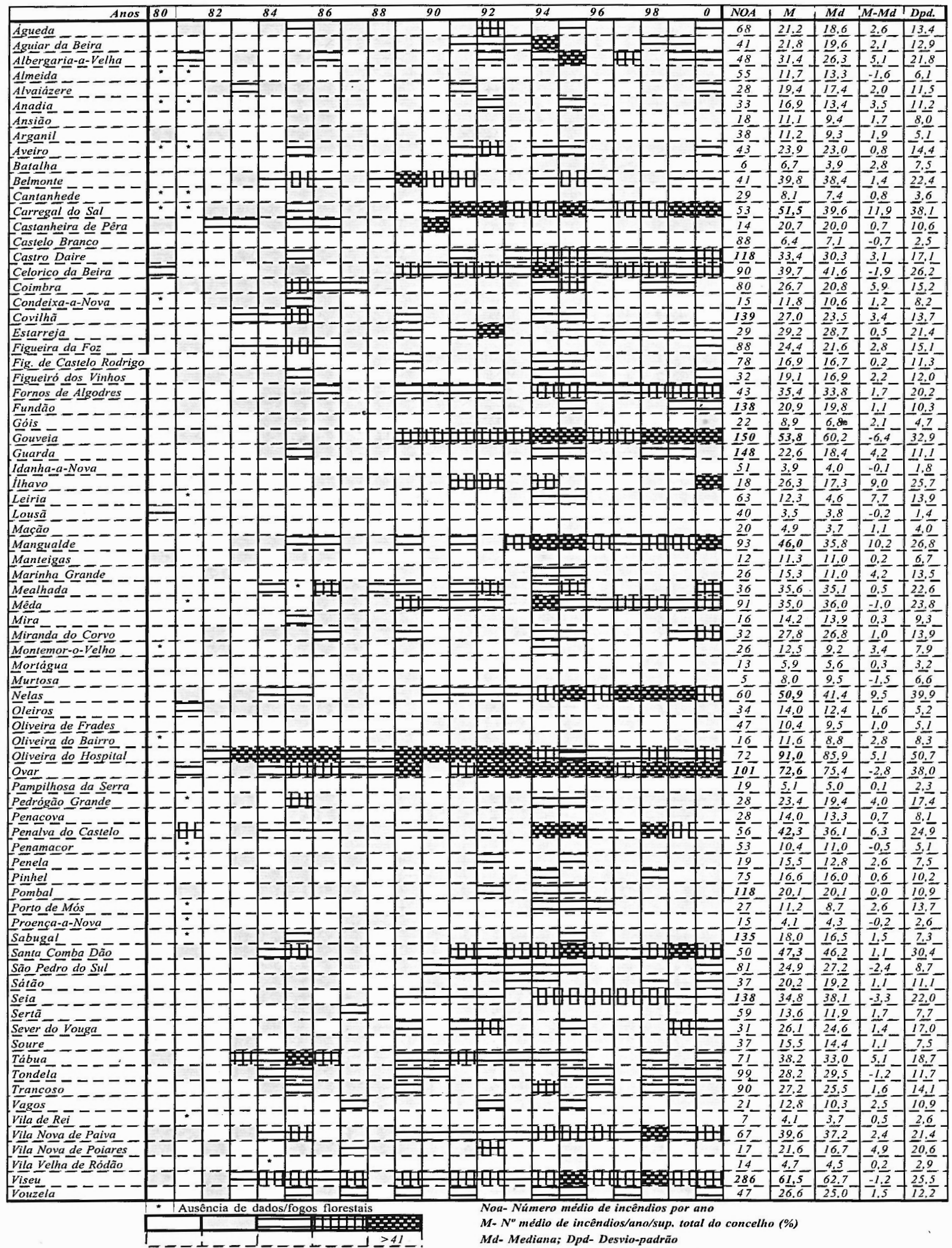

Fig. 3 - Análise estatísticn do número de ocorrências, por concelho (1980-2000) 
territorium 9.2002
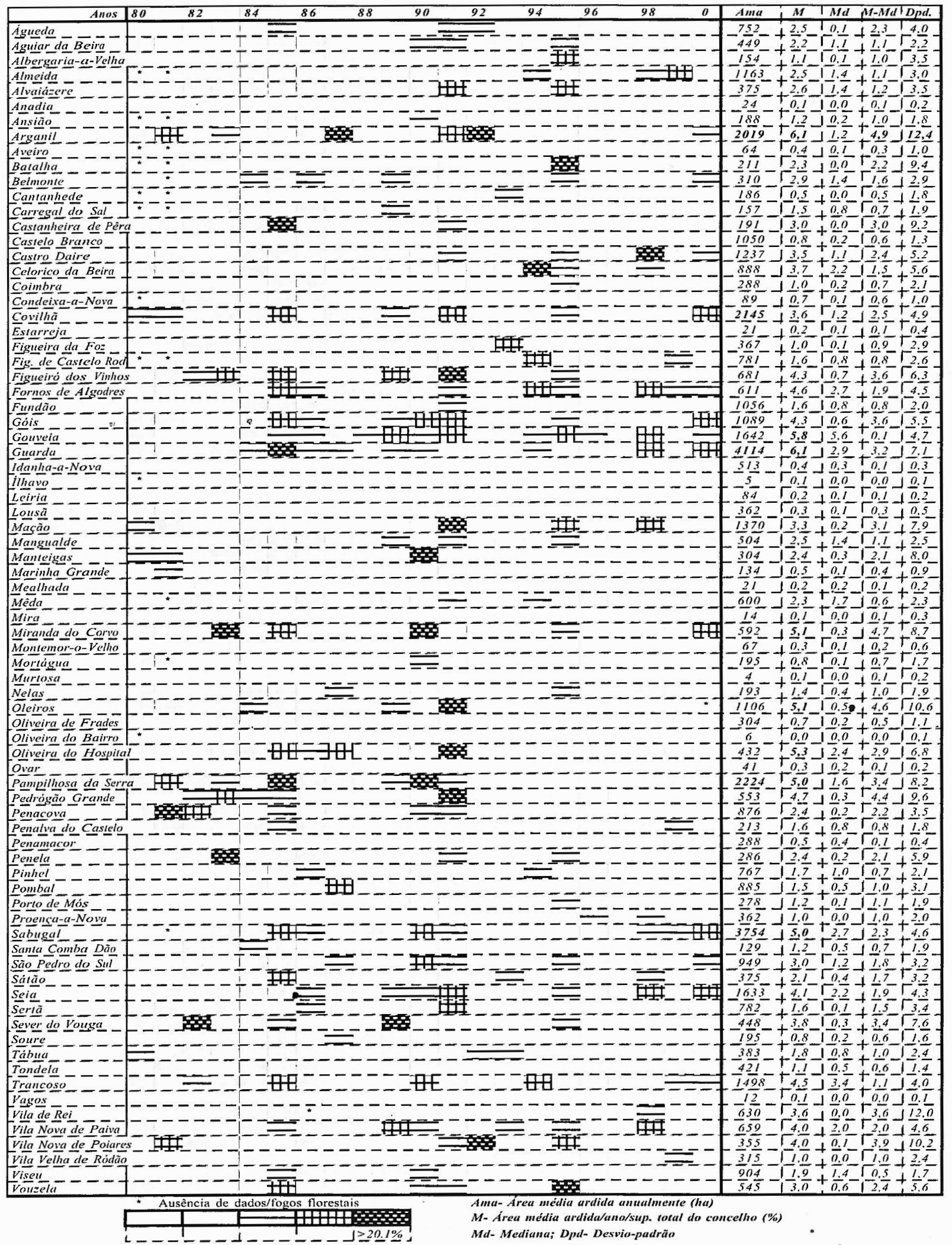

M- Area media ardidalano/sup. rotal do concelho (\%)

Mal-Mediana; Dpt- Desvio-padräo

Fig. 4 - Análise estatística das áreas ardidas, por concelho (1980-2000) 
É sabido que o conjunto anual ardido varia principalmente com as condições meteorológicas estivais, mas também com a quantidade de combustível disponível, pois uma época particularmente calamitosa em incêndios vai reduzir, pelo menos no ano seguinte, a massa inflamável disponível. E resultam incontestáveis as fortes relações entre os volumes ardidos em $1985,1989^{(1)}, 1991,1995$ e a intensa secura dos verões, na quase totalidade do país.

Não obstante, uma observação individualizada aos concelhos da R.C. deixa transparecer, além da desigual apetência do espaço geográfico aos incêndios florestais, o carácter cíclico assumida por este fenómeno em alguns municípios, em especial nos mais dizimados. Por exemplo, entre os concelhos que registaram 2 anos com uma área ardida superior a $20 \%$ do respectivo território (Arganil, Miranda do Corvo, Pampilhosa da Serra e Sever do Vouga) pode constatar-se que o intervalo que os separou oscilou entre 6 e 10 anos, ao passo que em outros (Batalha, Celorico da Beira, Castanheira de Pêra, Castro Daire, Figueiró dos Vinhos, Guarda, Mação, Manteigas, Vila de Rei, V. N. Poiares e Vouzela) apenas se assinalou um ano com valores superiores aos indicados.

Com uma percentagem ardida anual a variar entre os 10 e os $20 \%$ do respectivo território concelhio sobressai um maior número de municípios, cuja frequência se pode elevar até 4 anos, sendo disso exemplo Góis e Gouveia. Nestas duas unidades, as oscilações interanuais de incêndios, susceptíveis de alcançar estas proporções alargaram-se entre um máximo de 9 anos e a ocorrência consecutiva de dois anos com volumes superiores a $10 \%$ da respectiva superfície total.

Se nos fixarmos no patamar dos $5 \%$, verificamos que a repetição de incêndios que atinge este volume sofre um incremento, chegando a alcançar os 11 anos no município de Gouveia, 9 no da Guarda e 7 no Sabugal, Góis e Seia. Nestes casos, odesenvolvimento de fogos que totalizam uma área ardida superior a 5\% do respectivo território, manifestaram-se sucessivamente até um máximo de 4 anos em Gouveia, na Guarda e em Pedrogão Grande, e de 3 anos nos restantes concelhos identificados. A ocorrência repetida de 2 anos, contínuos, com áreas ardidas acima do limiar antes considerado ocorre com grande frequência em qualquer dos concelhos mais assolados pelo fogo.

Esta constatação permite, de certa forma, reequacionar algumas das relações de causalidade frequentemente sugeridas na justificação dos fogos florestais, nomeadamente as que se associam às condições climáticas e, em especial, meteorológicas. Com efeito,

(1) Recorda-se, a propósito desse ano, o trabalho realizado por L. LOURENÇO e A. B. GONÇALVES (1990) intitulado "As situaçôs meteorológicas e a eclosão - propagação dos grandes incêndios florestais registados durante 1989 no Centro de Portugal". se em determinados anos a componente climática desempenha um papel de destaque, outros há em que concorre com um papel subsidiário, encontrando-se o conjunto de causas e factores de desenvolvimento dos incêndios a nível municipal, principalmente, na eficácia do primeiro ataque e, depois, em outras circunstâncias como o relevo ou o tipoe a quantidade de combustíveis disponíveis.

\section{A desigual sensibilidade dos concelhos da Região aos fogos florestais: uma classificação}

A análise dos incêndios florestais e das respectivas áreas ardidas em cada um dos concelhos da R.C permite a sua hierarquização em função da maior ou menor sensibilidade ao fogo, logo com um risco histórico de incêndio desigual.

Com efeito, das vários apreciações efectuados à distribuição dos incêndios (L. LOURENÇo \& P. MALTA, 1993; L. Lourenço \& A. B.GonçALVES, 1998) ficou evidente a presença de áreas especialmente favoráveis à eclosão de incêndios, assinalando, em consequência, um elevado número de ocorrências anuais, enquanto em outras, as vastas áreas ardidas podem contrastar com um total de fogos insignificante. Por último, são de destacar as unidades que combinam grande densidade de fogos com amplas manchas incineradas.

Neste contexto, parece adquirir algum sentido a separação do risco histórico de incêndio em duas componentes complementares ${ }^{(2)}$ : a primeira ligada fundamentalmente ao risco de ignição ou eclosão de incêndios florestais (tendo por base a densidade anual de ocorrências), enquanto a segunda, mais associada à sua propagação ou gravidade (apoiada na inter-relação entre as áreas efectivamente ardidas e a correspondente superfície municipal, pelo que o respectivo valor se expressa em percentagem).

Da intercepção destes dois parâmetros, através de uma matriz de dupla entrada ou de contingências (G. Chadule, 1994, p. 83), emerge um quadro complexo de relações, susceptível de dar indicações sobre as potencialidade locais de incêndio, o que permite a sua diferenciação e especificaçãoem função da desigual aptidão na geração e propagação das chamas, mas também inferir sobre o êxito das intervenções (dependente da detecção inicial, do acesso ao local do fogo, das disponibilidades de meios técnicos e humanos, entre outros).

\footnotetext{
(2) L. LOURENÇO (1992, 1994, 1998) avaliou a componente histórico-geográfica do risco de incêndio florestal por concelho, através da conjugação da área ardida (classificada como um factor de risco proporcional à incidencia de causas de natureza física) com o número de incêndios (mais relacionados com causas humanas), definindo 3 situações de risco (Baixo, Médioe Alto) e dentro de cada uma destas demarcou 3 sub-classes, nos dois primeiros trabalhos, e 5 classes de risco, no último trabalho. A metodologia aqui utilizada não diferiu significativamente da utilizada por este Investigador , com excepção dos limiares e do número de classes.
} 
A simples associação entre estas duas variáveis, expressas em valores relativos por forma a evitar as distorções introduzidas pela desigual superfície concelhia e assim conseguir uma certa uniformização entre as mesmas, permitir-nos-ia, de forma muito elementar, a individualização de múltiplas combinações, mas porque o seu número se adivinha claramente exagerado, decidimos reagrupá-los em 4 grandes conjuntos (figura 5).
Num primeiro conjunto integram-se os concelhos com um risco de eclosão e de propagação que pode ser qualificado de baixo a moderado, pois a densidade anual de ignições não ultrapassa as 20 ocorrências e o conjunto médio ardido (1980-00), em relação à superfície total concelhia, é inferior a $1 \%$. Faz parte deste grupo um grande número de concelhos da faixa litoral do Centro e alguns da Beira Interior Sul.

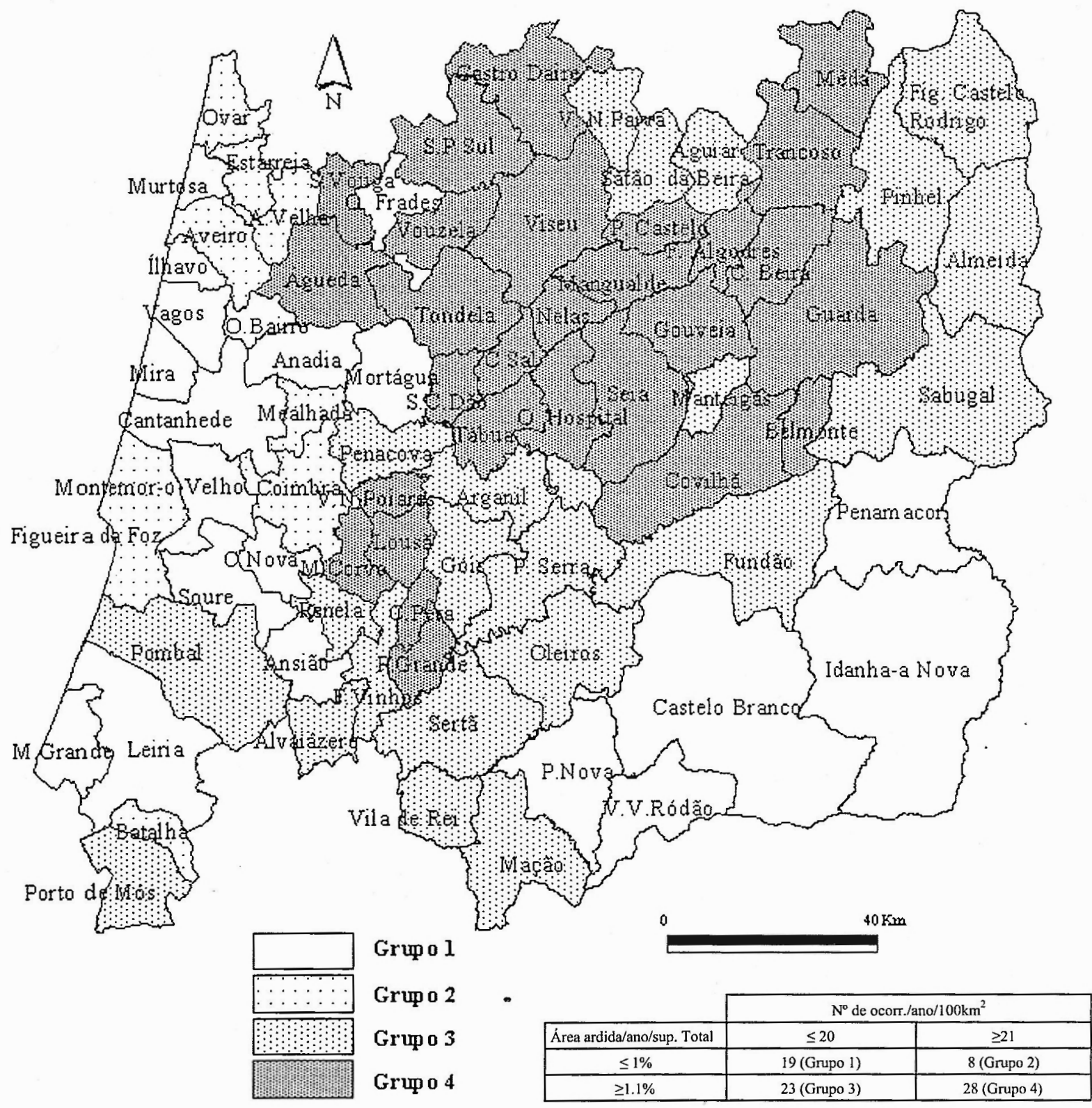

Fig. 5 - Classificação dos concelhos da Região Centro em função do número de ocorrências $/ a n o / 100 \mathrm{~km}^{2}$ e percentagem de áreas ardidas/ano/ superfícic total (1980-2000). 
O segundo grupo abrange os municípios que registam anualmente uma densidade de incêndios superior a 21 ocorrências, apesar das respectivas áreas médias incineradas terem sido inferiores a $1 \%$. Integram este conjunto 8 concelhos da R.C. sendo eles: Albergaria-a-Velha, Oliveira de Frades, Tondela, Aveiro, Coimbra, Estarreja, Figueira da Foz, Ílhavo, Mealhada, Ovar e Sta Comba Dão.

Do terceiro conjunto fazem parte os concelhos que, embora registemum reduzido númerode incêndios, têm áreas ardidas, em média, muito significativas, ou seja o respectivo risco de propagação poderá ser qualificado entre alto e máximo. Nele se inserem quase todos os concelhos do Pinhal Interior Sul, Pombal, Batalha, Porto de Mós, Figueira de Castelo Rodrigo, Almeida e Pinhel, Aguiar da Beira, Sátão e Manteigas

O quarto conjunto congrega os concelhos que revelam a maior apetência para os incêndios, quer em termos de ocorrências quer, no que respeita às áreas médias ardidas anualmente. Associa, consequentemente, um vasto leque de municípios, mais precisamente 28 , cujo risco de eclosão e propagação se pode caracterizar entre alto e extremo.

É nestes dois últimos grupos de concelhos, que abarcam a quase totalidade dos municípios da Beira Interior Norte, Serra da Estrela, Pinhal Interior Norte, Pinhal Interior Sul e margem NNE da sub-região do Dão-Lafões que os incêndios têm atingido maior gravidade. Por isso lhe dedicaremos mais atenção.

\section{Incêndios florestais - aspectos geohumanos da sua ocorrência}

Quando se procura explicar a incidência e a dimensão dos incêndios que ocorrem no nosso país, as características mediterrâneas do clima assumem de imediato um papel de destaque, continuamente ressaltadas pelos estudiosos que sobre esta questão se têm debruçado (F. Rebelo, 1980; L. Lourenço, 1991, 1992, 1995; L. LOURENÇO \& A. B.GonçALVES, 1989; C. Ramos \& J. Ventura, 1992; L. Cunha \& A. B. Gonçalves, 1994; A. Nunes, 2000, p. 55). Não obstante, às causas climáticas e meteorológicas associam-se sempre outras, da mesma natureza (como, por exemplo, as características morfológicas e biogeográficas) ou dependentes do contex to humano das áreas onde se desenvolvem (população residente, actividades sócio-económicas, modos de vida dos grupos humanos).

Torna-se, portanto, necessáriauma análise integrada do território por forma a descobrir potenciais relações, causais, entre a incidência de fogos e os agentes que os condicionam, no intuito de reconhecer alguns dos elementos-chave responsáveis pela sua geração e propagação, pois só desta forma se poderá prevenir e combater a sua manifestação.

Na exploraçãodos potenciais factores intervenientes na génese dos incêndios e na extensão das manchas ardidas, definiram-se e quantificaram-se múltiplas variáveis que se enquadram em 3 grupos de famílias: demográficas, sócio-económicas e componente ambiental (quadro $1 \mathrm{em}$ anexo), as quais se inter-relacionam através do Coeficiente de Correlação Linear, com as informações disponíveis sobre incêndios florestais.

\section{Região Centro (78 concelhos $)^{(3)}$}

Quando se tentou aferir a reciprocidade entre o conjunto dependente (incêndios florestais) e o conjunto independente (variáveis geohumanas), os resultados obtidos apresentaram-se pouco consistentes, com excepção dos detectados entre as percentagens médias anualmente ardidas, em relação à superfície total concelhia, e o índice de rugosidade topográfica ${ }^{(4)}$ (A. R. Pereira, C. Ramos \& Colaboradores, 2000, p. 18-19), cujo valor de $\mathbf{r}$ apurado foi de 0.6 . Por conseguinte, serão os contrastes orográficos regionais, expressos pelo indicador de rugosidade topográfica, pela influência que exercem em outras variáveis de natureza física e biofísica, como por exemplo a distribuição das variáveis meteorológicas (temperaturas, precipitação, insolação, etc.), cobertura vegetal, declives ou rede viária, os factores mais preponderantes na difusão das chamas, mas igualmente os decisivos na acessibilidade ao local do fogoe, consequentemente, no seu combate.

Com significado estatístico foram ainda detectadas outras associações que merecem ser salientadas, nomeadamente as que resultam do cruzamento do valor médio anual de incêndios com a população residente $(r=0.43)$ e com a prática da pastorícia, em particular quando o gado ovino predomina $(r=0.35)$. Todavia, o valor desta última associaçãoéligeiramente ampliado, para 0.45 , se utilizarmos os respectivos valores relativos, isto é a densidade de incêndios e de gado ovino, por cada $\mathrm{km}^{2}$. Com o mesmo valor e sentido, sobressai uma outra correlação, definida entre a densidade de cabeças e a percentagem de área ardida, anualmente, por concelho.

(3) Para a dimensão da série analisada $(n=78)$ existe uma correlação linear significativa sempre que os valores em absoluto sejam superiores a [0.18|, para uma margem de erro de $10 \%$, a $\mid \mathbf{0 . 2 2}$ ], para uma margem de $5 \%$, $|\mathbf{0 . 2 5}|$ para $2 \%$ e $|\mathbf{0 . 2 6}|$ para uma margem de erro de $1 \%$ (G. Chadule, 1994 , p.195-196).

(4) Obtido da razão entre a amplitude altimétrica e a raiz quadrada da área do concelho (adaptação de I. de Melton). 
Este par de associações sugere-nos mais uma vez (A. NunEs, 2000, 2001) que a actividade pastoril é, de entre as variáveis correlacionadas, a que melhor se associa aos incêndios florestais, em particular ao número de ocorrências e, eventualmente, às áreas ardidas.

Uma outra variável a marcar a dispersão geográfica das áreas ardidas, pelas relações inversas demonstradas $(\mathrm{r}=-0.41)$, é a variação da população nestas últimas décadas. De facto, são os municípios mais fortemente abalados pelo êxodo rural e agrícola que registam, de um modo geral, as maiores percentagens anuais ardidas, resultantes em grande parte da menor comparência do Homem nas actividades agrárias, com o consequente abandono dos campos de cultivo e das explorações florestais.

Mas, porque as assimetrias espaciais na Região Centro são expressivas e o resultados das correlações se evidenciam algo frágeis, achámos pertinente a aplicação do mesmo Coeficiente de Correlação aos diferentes conjuntos de concelhos, agregados em função de uma certa homogeneidade no que se refere à incidência e gravidade dos incêndios florestais. O objectivoé obter informações com maior profundidade e rigor sobre o modo como se relacionam, numericamente, estes fenómenos e a conjuntura geohumana dominante. A este propósito, acrescenta-se ainda a necessidade de descobrir se os principais factores responsáveis pelos incêndios são comuns em cada um dos conjuntos definidos, ou se, pelo contrário, procedem de condicionantes específicas intra-concelhias.

Atendendo a que os incêndios evidenciam maior gravidade nos grupos 4 e 3 , dedicar-lhe-emos maior atenção, surgindo assim a sua análise em primeiro lugar e mais aprofundada, ao passo que nos grupos 2 e 1 serão apenas realçadas as principiais correlações detectadas.

\section{GRUPO 4 ( 28 concelhos)}

A aplicação do Coeficiente de Correlação Linear ao grupo de concelhos mais afectados pelos fogos florestais ${ }^{(5)}$ sugere as seguintes associações entre as variáveis, depois de confrontadas par-a-par (figura 6):

- A população total surge como o factor protagonista dos incêndios ocorridos neste conjunto de concelhos, pois o respectivo coeficiente de correlação/regressão

(5) Para a dimensão da série analisada $(n=28)$ existe uma correlação linear significativa sempre que os valores em absoluto sejam superiores a $[0.29 \mid$, para uma margem de erro de $10 \%$, a $|0.32|$, para uma margem de $5 \%,|0.40|$ para $2 \%$ e $|\mathbf{0 . 4 5}|$ para uma margem de erro de $1 \%$ (G. Chadule, 1994, p. 195-196). $\left(r=0.83, r^{2}=0.69\right)$ explica, por si só, cerca de $70 \%$ da variância global. São, no entanto, de salientar outras variáveis pelo correspondente contributo, positivo, no volume médio anual de ocorrências, designadamente o total de cabeças de gado miúdo e a população absoluta integrada no sector primário.

- Quando se procura compreender a densidade de ocorrências/ano/100 km², os totais absolutos da população residente e das cabeças de gado miúdo perdem relevância e passam a deter maior preponderância os respectivos valores relativos, isto é, a densidade populacional e de pequenos ruminantes, especialmente se predominarem ovinos.

- As variações espaciais das manchas de mato anualmente consumidas pelas chamas, que representam nestes concelhos uma grande fatia da área total incinerada, relacionam-se de forma positiva e claramente explícita com duas variáveis intimamente conectadas; a SAU (Superfície Agrícola Útil), ao definir um coeficiente de 0.84 , e o total de caprinos e ovinos declarados a nível municipal, cujo r apurado é de 0.77. Por conseguinte, o volume médio incinerado em cada ano, a oscilar entre os 157 ha de Carregal do Sal e os mais de 4100 ha da Guarda, relaciona-se exactamente com as mesma variáveis.

- No que se refere às áreas médias de povoamento ardido, os coeficientes de correlação sugerem que a variabilidade inter-municipal está dependente da população total residente $(r=0.63)$ e das manchas de florestas e matas existentes $(r=0.56)$;

- A avaliação dos coeficientes decorrentes da associação das áreas ardidas, em termos percentuais, com as potenciais variáveis explicativas mostra associações pouco significativas, pelo menos para um intervalo de confiança de $99 \%$, identificando-se, no entanto, para uma margem de errode $5 \%$, correlações, de sentido negativo, entre esta variável a percentagem florestada (matas e florestas), em relação à área total administrativa.

- Das inter-relações entre as percentagens de povoamento e mato incinerado com o conjunto de variáveis explicativas são de assinalar associações com peso estatístico, no sentido directo, com as variações relativas da população e com o total de cabeças de gado miúdo. Para os valores relativos de mato ardido, o coeficiente reforça ainda outras afinidades ao aproximar esta variável, no sentido inverso, com as manchas de povoamento, densidades populacionais e variações demográficas em termos relativos.

- No que concerne à dimensão média dos incêndios, calculada para estes 21 anos, é de destacar a sua interdependência em relação a três variáveis: no sentido positivo, sobressai a SAU total e o índice de rugosidade do concelho, enquanto no sentido negativo destaca-se a densidade populacional. 


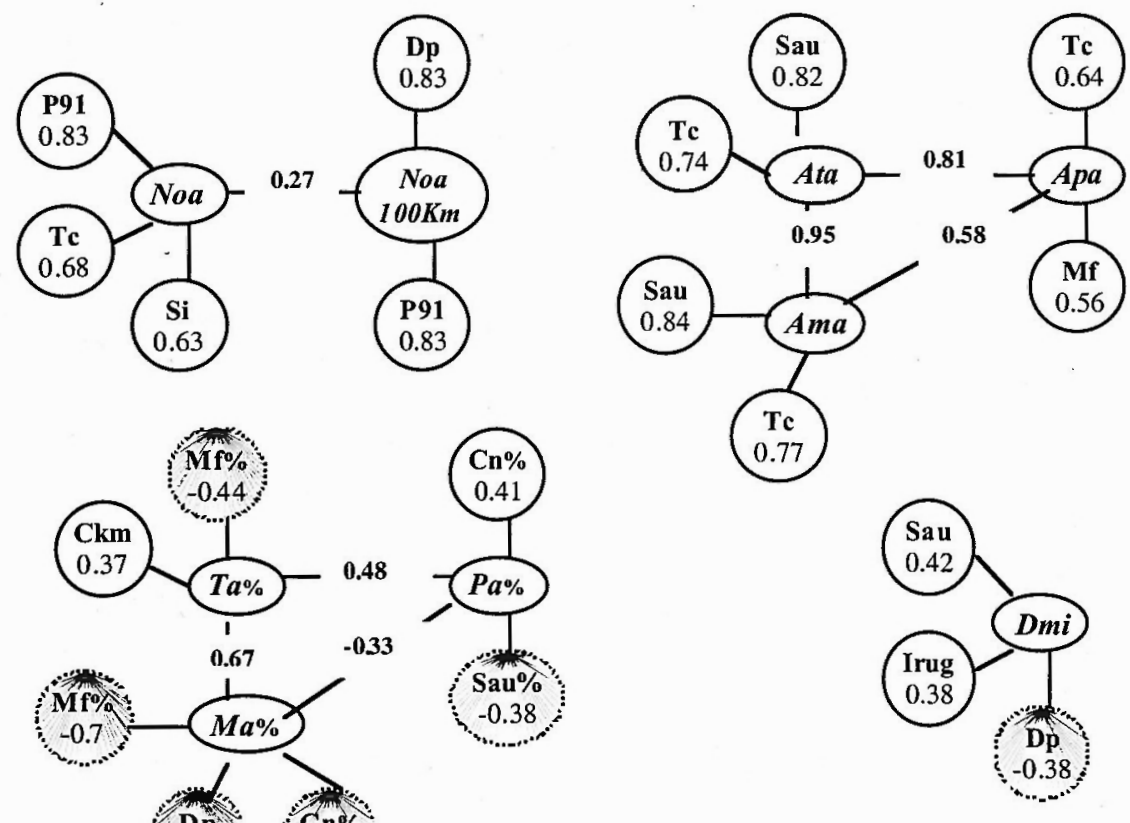

(- Correlação positiva; --- Correlação negativa)

\begin{tabular}{|c|c|}
\hline SIGLAS & DESIGNAção \\
\hline Noa & Número de ocorrências registadas, em média, por ano (1980-2000) \\
\hline Noa $/ 100$ km $^{2}$ & Número de ocorrências registadas, em média, por ano $(1980-2000)$ em cada $100 \mathrm{~km}^{2}$ \\
\hline Ata & Área média ardida por ano $(1980-2000)$ \\
\hline Apa & Area de povoamento ardido, em média por ano (1980-2000) \\
\hline Ama & Área de mato ardido, em média por ano (1980-2000) \\
\hline $\mathbf{T a} \%$ & Total ardido, em percentagem, em relação à superfície total concelhia (1980-2000) \\
\hline $\mathbf{P a} \%$ & Povoamento ardido, em percentagem, em relação à superficie total concelhia $(1980-2000)$ \\
\hline $\mathbf{M a} \%$ & Mato ardido, em percentagem, em relação à superficie total concelhia (1980-2000) \\
\hline Dmi & Dimensão média dos incêndios (1980-2000) \\
\hline P91 & População residente (1991) \\
\hline Dp & Densidade populacional (1991) \\
\hline Ce & Crescimento efectivo (1960-2001) \\
\hline $\mathrm{Cn} \%$ & Crescimento efectivo, em percentagem (1960-2001) \\
\hline Tenv & Taxa de envelhecimento (1991) \\
\hline Si & População integrada no sector primário (1991) \\
\hline $\mathbf{S i \%}$ & População integrada no sector primário, em relação à população total (1991) \\
\hline Tc & Total de cabeças de gado miúdo (1989) \\
\hline $\mathrm{Ckm}^{2}$ & Número de cabeças de gado por $\mathrm{km}^{2}$ \\
\hline Sau & Superficie agrícola útil (ha)- (1989) \\
\hline Sau \% & Percentagem de Superficie agrícola útil em relação à área total administrativa \\
\hline Mf & Matas e florestas (ha)- (1989) \\
\hline Mf\% & Percentagem de matas e florestas em relação à área total administrativa \\
\hline Irug & Índice de rugosidade (A. R. P EREIRA, C. R AMOS \& COL, 2000) \\
\hline Ins & Insolação, em múmero de horas anuais (A. R. P EREIRA, C. R AMOS \& COL, 2000) \\
\hline Tmq & Temperatura média do mês mais quente (A. R. P EREIRA, C. R AMOS\& COL., 2000) \\
\hline $\mathbf{N b}$ & Número de bombeiros \\
\hline Nb10km ${ }^{2}$ & Número de bombeiros por cada $10 \mathrm{~km}^{2}$ \\
\hline
\end{tabular}

Fig. 6 - Gráfico das correlações entre as variáveis dependentes (incêndios florestais) e as variáveis independentes (aspectos geohumanos) neste grupo de concelhos (ver designação das siglas no quadro). 


\section{GRUPO $3(23 \text { concelhos })^{(6)}$}

Neste conjunto de concelhos, o Coeficiente de Correlação sugere, depois de confrontadas as variáveis, as seguintes associações estatísticas:

- Do rol de elementos relacionados, o total de cabeças de gado miúdo, a SAU e a população absoluta dominam, no sentido positivo, a distribuição espacial dos incêndios florestais registados nestas últimas duas décadas.

- Quanto ao número médio anual de incêndios/ $100 \mathrm{~km}^{2}$ os coeficientes obtidos apenas se mostram expressivos e de sinal positivo, para uma margem de erro de $5 \%$, com a percentagem de SAU em relação à área total concelhia e com a densidade de ovinos.

- A SAU total, com um coeficiente de 0.65 , e o crescimentoefectivo da população, com um coeficiente negativo de 0.79 , são as variáveis que melhor se relacionam com a área média de mato ardida anual-

(6) Para a dimensão da série analisada $(n=23)$ existe uma correlação linear significativa sempre que os valores em absoluto sejam superiores a 10.33|, para uma margem de erro de $10 \%$, a $|0.40|$, para uma margem de $5 \%$, 10.46| para $2 \%$ e $|0.50|$ para uma margem de erro de $1 \%$ (G. Chadule. 1994, p. 195/6). mente, ao passo que o total de povoamento dizimado apenas se associa, no sentido directo, com as taxas de envelhecimento $(r=0.48)$.

- Com influência no comportamento espacial da área média incinerada surgem, claramente, as transformações sociodemográficas ocorridas nestas últimas décadas, derivadas das mutações populacionais, marcadas por um declínio em quase todos os concelhos e por um aumento da taxa de envelhecimento. Assim sendo, as áreas médias ardidas, a oscilar em termos absolutos entre os 286 ha de Penela e os 3750 ha do Sabugal, mostram um relação inversa com as variaçães da populaçãoe directas com as taxas de envelhecimento.

- Porque este conjunto congrega concelhos com uma superfície muito contrastante, importa a análise das respectivas variáveis relativas, que registam correlações particularmente curiosas face ao conjunto de concelhos anteriormente apresentados. Assim, pelas correlações inversas detectadas entre a percentagem ardida anualmente, relativamente à superfície concelhia, a densidade de cabeças de gado miúdo e a percentagem de população integrada no sector primário, pode concluir-se que estas duas últimas variáveis detêm um efeito inibidor na propagação

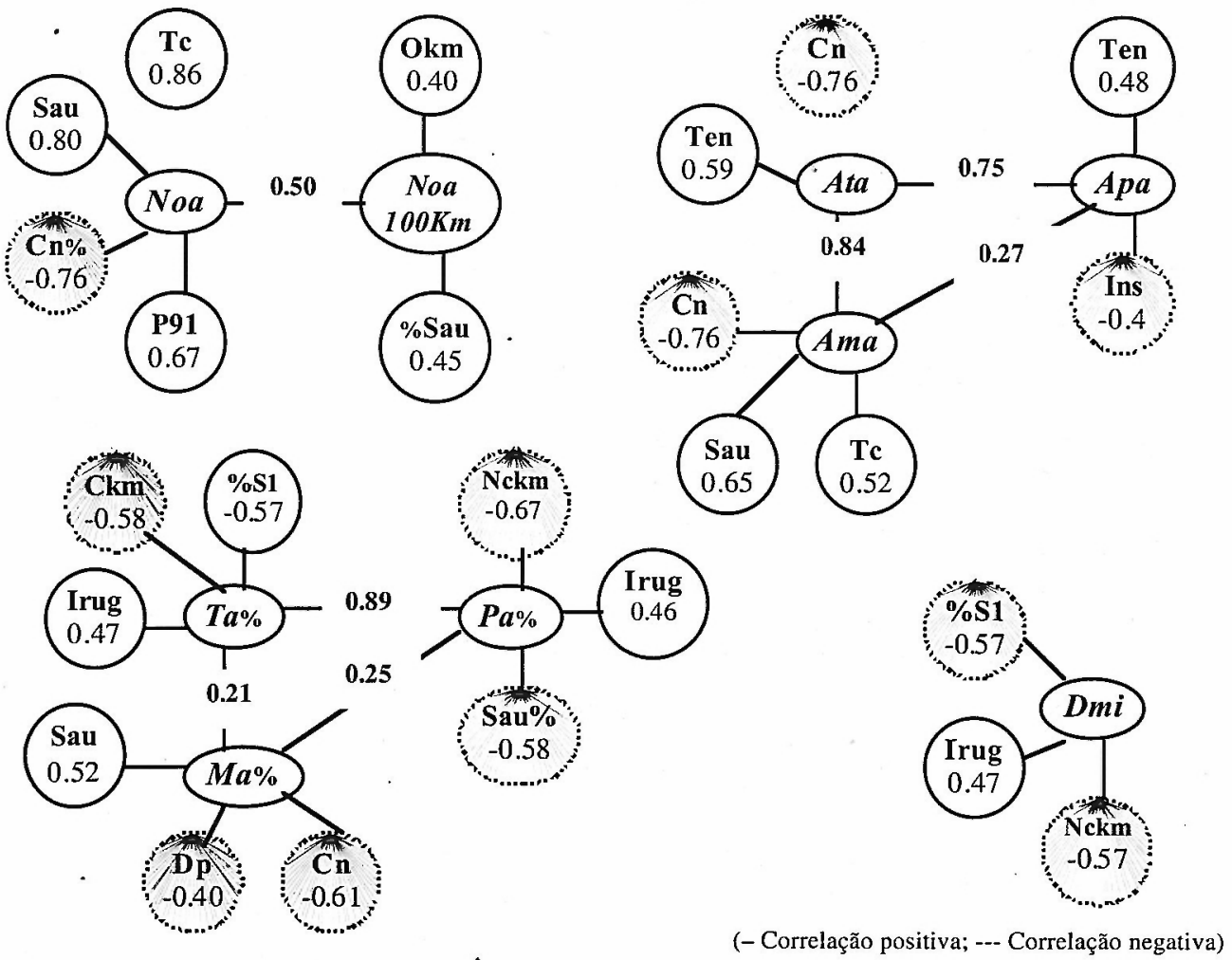

Fig. 7 - Gráfico das correlações entre as variáveis dependentes (incêndios florestais) e as variáveis independentes (aspectos geohumanos) neste grupo de concelhos (ver designação das siglas no quadro da figura 6). 
dos incêndios e consequentemente nas áreas varridas pelo fogo, sobretudo nas manchas de povoamento.

- Em relação à dimensão média dos incêndios, ela parece relacionar-se, nestes concelhos, de forma directa, com o envelhecimento da população e com a rugosidade topográfica e, de forma inversa, com o número de cabeças de gado, por $\mathrm{km}^{2}$.

\section{GRUPO $2(8 \text { concelhos })^{(7)}$}

Neste conjunto de concelhos, porque o seu efectivo é reduzido, apenas se salientam os coeficientes de correlação mais significativos, destacando-se assim:

- A relação inversa entre o número de bombeiros por $\mathrm{km}^{2}$ e o total ardido, quer em termos absolutos $(r=-0.84)$, quer em termos relativos $(r=-0.84)$, e a dimensão média alcançada pelos incêndios $(\mathrm{r}=-0.88)$

- A visível afinidade, positiva, entre o número de ovinos e as manchas de mato carbonizado $(\mathrm{r}=0.83)$.

- $O$ indicador de rugosidade surge como um factor decisivo na percentagem de matos ardidos $(\mathrm{r}=0.82)$.

\section{GRUPO I (19 concelhos $)^{(8)}$}

Ainda que, em termos relativos, os incêndios florestais não detenham uma importância expressiva nestes concelhos, quando avaliados em termos absolutos surgem alguns valores bastante elevados, nomeadamente em Castelo Branco (com uma média de 88 incêndios ao ano e com cerca de 1050 ha ardidos/ ano) e em Idanha-a-Nova (51 incêndios e mais de 500 ha ardidos, por ano). São, por isso, de destacar as seguintes correlações:

- O número médio de ocorrências anuais associa-se directamente com as manchas florestais $(r=0.80)$, SAU $(r=0.75)$, número de cabeças de gado miúdo $(\mathrm{r}=0.60)$ e só, por último, com a população residente $(r=0.59)$, enquanto a sua densidade se relaciona, no sentido positivo, com a população relativa $(\mathrm{r}=0.66)$ $\mathrm{e}$, de forma inversa, com as taxas de envelhecimento $(\mathrm{r}=-0.58)$, número de ovino por $\mathrm{km}^{2}(\mathrm{r}=-0.58)$ e com o número total de horas de sol por ano.

- O valor médio anual de matos ardidos mostra reciprocidade com a SAU $(r=0.93)$ e com o total de

(7) Para a dimensão da série analisada $(\mathrm{n}=8)$ existe uma correlação linear significativa sempre que os valores em absoluto sejam superiores a |0.55|, para uma margem de erro de $10 \%$, a $|0.67|$, para uma margem de $5 \%$, |0.71| para $2 \%$ e $\mid 0.83$ | para uma margem de erro de $1 \%$ (G. Chadule, 1994, p.195-196).

(8) Para a dimensão da série analisada $(\mathbf{n}=19)$ existe uma correlação linear significativa sempre que os valores em absoluto sejam superiores a |0.37|, para uma margem de erro de $10 \%$, a $\mid \mathbf{0 . 4 3}$, para uma margem de $5 \%$, |0.50| para $2 \%$ e $|\mathbf{0 . 5 5}|$ para uma margem de erro de $1 \%$ (G. Chadule, 1994, p.195-196). cabeças declaradas a nível municipal $(r=0.94)$, ao passo que as variáveis ambientais mais importantes na sua distribuição são a insolação média anual $(\mathrm{r}=0.72)$ e, consequentemente, a temperatura do mês mais quente $(\mathrm{r}=0.65)$. A densidade populacional $(\mathrm{r}=-0.64)$ e o número médio de bombeiros por $10 \mathrm{~km}^{2}(\mathrm{r}=-0.66)$ associam-se de forma negativa.

- As percentagens de matos ardidos anualmente associam-se, no sentido inverso, à percentagem de população integrada no primeiro sector de actividade $(r=-0.70)$, à densidade populacional $(r=-0.60)$ e ao crescimento efectivo, registado nestas últimas 4 décadas $(r=-0.49)$. Com influência positiva destacam-se, em primeiro lugar, a densidade de pequenos ruminantes $(r=0.63)$ e, em especial, se predominarem os caprinos $(r=0.82)$, bem como a taxa de envelhecimento $(\mathrm{r}=-0.59)$ e as temperaturas médias do mês mais quente $(r=0.63)$. Relativamente aos totais anuais ardidos, sobressaem igualmente estas 3 últimas variáveis referidas.

- As dimensões médias dos incêndios neste conjunto de concelhos relaciona-se, no sentido inverso, com a densidade populacional $(\mathrm{r}=-0.64)$ e com o número de bombeiros por cada $10 \mathrm{~km} 2(\mathrm{r}=-0.56)$, manifestando afinidades, de sinal positivo, com a temperaturas máximas alcançadas no mês mais quente $(r=0.72)$, insolação média anual $(r=-0.71)$, densidade de gado miúdo $(r=0.62)$ e taxas de envelhecimento $(r=0.60)$.

\section{Conclusões}

Parece ficar evidente, depois desta análise, que o cenário de incêndios catalogado de calamitoso, nestes últimos anos, se deve principalmente à destruição de uma série de equilíbrios ambientais, sócio-demográficos e económico-culturais historicamente cimentados, cujas repercussões mais visíveis se traduziram num acréscimo dos combustíveis disponíveis para arder. Por efeito dessas transformações, bem mais agudas no Interior do país, assistiu-se à crescente homogeneização da paisagem, não só pelo abandono das terras aráveis, sujeitas na sequência às vicissitudes do meio, mas também devido ao crescente uso monoespecífico do território, com a utilização de associações altamente inflamáveis.

Nestas circunstâncias, sempre que os incêndios deflagram, devido a causas humanas ou naturais, as respectivas consequências tornam-se mais gravosas do que nas décadas precedentes, quando o aproveitamento da biomassa era contínuo e a prática agrícola muito mais activa, subtraindo o material combustível das matas e promovendo, desta forma, a sua protecção.

Insiste-se, portanto, na necessidade e urgência de estratégias que visem, fundamentalmente, a protecção dos concelhos mais vulneráveis ao fogo, os quais 
emergem precisamente nos espaços mais periféricos da R.C. A evidente falta de efectivos demográficos, o envelhecimento da população, o decréscimo da actividade agrária e os fortes atrasos estruturais (quer do ponto de vista físico, quer do ponto de vista humano), terão de ser minorados através de um correcto ordenamento e de uma gestão integrada da floresta.

Por outro lado, e porque a população total e as respectivas actividades agrícolas, evidenciadas quer pela SAU quer pelo total de gado miúdo, detêm um papel preponderante na geração de incêndios florestais, será de todo o interesse desenvolver campanhas de sensibilização e prevenção de incêndios florestais, mas tambéme sobretudo apostar na consciencialização para a promoção da floresta enquanto recurso geoecológico.

Por tudo isto, torna-se imprescindível descobrir e reinterpretar a variedade de situações territoriais e sociais por forma a que os propósitos florestais e de conservação dos recursos naturais não estejam, logo à partida, condenados ao fracasso.

Assim, a eliminação ou pelo menos a redução dos combustíveis em determinadas áreas considera-se prioritária, podendo recorrer-se a técnicas variadas que poderão incluir desde desmatações manuais ou mecânicas, fogo controlado, uso de fotoquímicos, etc. Será, porventura, uma estratégia necessária para poder diminuir a severidade dos incêndios em certos territórios e impedir a sua trajectória para uma, anunciada, desertificação.

Bibliografia:

CHADULE, Groupe (1994)- Initiation aux pratiques statistiques en géographie. Masson, Collection Géographie, 202 p.

CUNHA, L., GONÇALVES, A. B. (1994)- "Clima e tipos de tempo enquanto características físicas condicionantes do risco de incêndio. Ensaio metodológico". Cadernos de Geografia, $\mathrm{n}^{\circ}$ 13, Coimbra, F. L. U. C., p. 3-13

LOURENÇO, L. \& GONÇALVES, A. B. (1990) - "As situações meteorológicas e a eclosão-propagação dos grandes incêndios florestais registados durante 1989 no Centro de Portugal". Comunicação apresentada no II Congresso Florestal Nacional, Porto, Separata, 8 p.
LOURENÇO, L. (1992) - "Avaliação do risco de incêndio nas matas e florestas de Portugal continental". Finisterra, XXVII, 53-54, Lisboa, p.115-140.

LOURENÇO, L. \& MALTA, P. (1993) - "Incêndios florestais em Portugal continental na década de 80 e anos seguintes". Finisterra, XXVIII, 55-56, Lisboa, p.261-277.

LOURENÇO, L. (1994) - "Sistemas de informação de risco de incêndio florestal". Actas do II EPRIF, Coimbra, p. 207-229.

LOURENÇO, L. (1995) - Serras de xisto do centro de Portugal. Contribuição para o seu conhecimento geomorfológico e geoecológico. Dissertação de Doutoramento em Geografia apresentada à Faculdade de Letras da Universidade de Coimbra, $756 \mathrm{p}$.

LOURENÇO, L. \& GONÇALVES, A B. (1998)- "Índice de risco histórico-geográfico de fogo florestal- uma proposta para Portugal Continental". Rev. Técnica e Formativa, Escola Nacional de Bombeiros, ano 2, $\mathrm{n}^{\circ}$ 6, p.16-27.

NUNES, A. N. (2000) - "O risco de incêndio florestal e prática da pastorícia em 4 concelhos da Serra da Estrela. Tentativa de correlação". Territorium, 7, Coimbra, p. 55-64.

NUNES, A. N. (2001) - Incêndios florestais no Parque Natural da Serra da Estrela. Dissertação de Mestrado em Geografia apresentada à Faculdade de Letras da Universidade de Coimbra, $237 \mathrm{p}$.

PEREIRA, A R; RAMOS, C. E COLABORADORES (2000)Contrastes espaciais concelhios de algumas componentes ambientais em Portugal continental. Centro de Estudos Geográficos, Lisboa, $39 \mathrm{p}$.

REBELO, F. (1980)- "Condições de tempo favoráveis à ocorrência de incêndios florestais”, Biblos, LVI, Coimbra, p. 653-673.

REBELO, F. (2001) - Riscos naturais e acção antrópica. Coimbra, Imprensa Universitária, $247 \mathrm{p}$.

RAMOS, C. \& VENTURA, J. E (1992)- "Um índice climático de perigo de incêndio florestal aplicado aos fogos florestais em Portugal". Finisterra, Lisboa, 53-54, p. 79-93.

WOLFANGO, F. de MACEDO; SARDINHA, A. M. (1993) - Fogos florestais. Lisboa, Publicações Ciência e Vida, Lda., $1^{\circ}$ e - $2^{\circ}$ volume, $342 \mathrm{p}$.

Outros documentos

- Incêndios florestais, Estatísticas do número de incêndios, áreas ardidas segundo o tipo de povoamento, por concelho, relativos aos anos de 1980 a 2000, Direç̧ão Geral das Florestas. 